\title{
Escarificação e adubação orgânica: efeito na recuperação estrutural de solo produzindo Tifton 85
}

\author{
Soil chiseling and poultry litter fertilization: effects on \\ soil structural recovery under Tifton 85 production
}

\author{
Giseli Colussi $^{\text {I }}$ Leandro Souza da Silva ${ }^{\text {II }}$ Evandro Antonio Minato ${ }^{\text {III }}$
}

\section{RESUMO}

A produção intensiva de forrageiras para fenação aumenta os riscos de degradação física do solo e a escarificação, associada ou não com a adubação orgânica, pode ser alternativa para a recuperação estrutural desses solos. Assim, objetivou-se avaliar os efeitos da escarificação do solo, da adubação orgânica e adubação mineral, na densidade e porosidade do solo e na produtividade da Tifton 85. O experimento foi conduzido em uma área cultivada por dez anos para feno com Tifton 85. Apenas a escarificação promoveu alterações significativas nos atributos físicos do solo, principalmente na profundidade de 0,03-0,08m, mantendo-se por pelo menos nove meses. O curto período entre a escarificação e o primeiro corte para fenação prejudicou a produtividade da Tifton 85, porém não houve diferença na produtividade acumulada entre os manejos do solo ao fim de uma estação de crescimento da pastagem. A produtividade foi maior para os tratamentos com reaplicação de nitrogênio mineral em relação à testemunha, sendo que a produtividade com o uso de cama de aves foi inferior à adubação mineral no somatório dos quatro cortes da gramínea.

Palavras-chave: Cynodon dactylon, escarificação, cama de aves, fenação.

\section{ABSTRACT}

The intensive forage production for hay increases the risk of soil physical degradation and soil chiseling, with or without organic and mineral fertilization, could be alternatives to soil structural recovery. The objective of this study was to evaluate the soil chiseling and poultry litter fertilization effects on soil bulk density and porosity and Tifton 85 production. The experiment was conducted in a soil with a ten years hay production with Tifton 85. Significant changes in soil physical properties occurred only with chiseling, especially at 0.03-0.08m depth, keeping for at least nine months. The short period between the first cut and chiseling harmed the Tifton 85 production, with no difference between the soil management in the end of Bermuda grass growing season. The productivity was higher in treatments with nitrogen reapplication. Tifton 85 with poultry litter produced less dry matter than with mineral fertilizer on the sum of four cuts of Bermuda grass.

Key words: Cynodon dactylon, chisel, poultry litter, hay production.

\section{INTRODUÇÃO}

O incentivo de órgãos governamentais e não governamentais à produção de leite no sudoeste do Paraná acarretou em aumento de áreas com cultivo de forrageiras para fenação, principalmente a Tifton 85 (Cynodon dactylon). Na região, o cultivo da Tifton 85 é realizado, geralmente, em solos de textura muito argilosa e, devido ao intenso tráfego de máquinas, muitas vezes sem controle da umidade, ocorre perda da qualidade física do solo, com diminuição da produtividade e qualidade da gramínea (GIAROLA et al., 2007). Devido à compactação, há redução da taxa de infiltração de água no solo e na quantidade de água disponível às plantas e, em períodos secos, dificuldades para o crescimento de raízes (BRAIDA et al., 2011), com reflexos na produtividade das culturas.

A problemática no estudo da compactação do solo é que tanto os solos como as culturas respondem de forma diferente ao fenômeno, acarretando em recomendações de manejo do solo,

\footnotetext{
'Programa de Pós-graduação em Ciência do Solo, Universidade Federal de Santa Maria (UFSM), 97105-900, Santa Maria, RS, Brasil. E-mail: colussi@agronoma.eng.br. Autor para correspondência.

"Departamento de Solos, UFSM, Santa Maria, RS, Brasil.

IIIPrograma de Pós-graduação em Agronomia, Universidade Estadual de Maringá (UEM), Maringá, PR, Brasil.
} 
muitas vezes, específicas para cada situação (solos, culturas e condições climáticas) (REICHERT et al., 2007). A maioria dos estudos para a minimização do efeito da compactação do solo é realizada em lavouras com culturas anuais, havendo poucos estudos com relação às pastagens perenes (COLET et al., 2009), e os existentes não são definitivos por que as plantas forrageiras possuem sistema radicular denso e as agressões provocadas pelos implementos agrícolas de preparo do solo, como o escarificador, podem reduzir a produtividade (BOMFIM et al., 2003).

Outro aspecto a ser considerado é que as gramíneas forrageiras são exigentes quanto à fertilidade do solo e, quando destinadas à fenação, demandam uma quantidade mais elevada de nutrientes, principalmente com relação ao nitrogênio e o potássio (REIS et al., 2005). Devido à contínua exportação de nutrientes, neste sistema, a adubação orgânica pode ser uma estratégia interessante, tendo em vista a liberação gradual dos nutrientes e a adição de matéria orgânica, podendo auxiliar na melhoria das propriedades do solo e no estabelecimento de microrganismos benéficos. No Brasil, o aumento da produção de aves gera grandes quantidades de resíduos orgânicos, os quais, desde que racionalmente utilizados, podem substituir ao menos em parte os adubos industrializados (WOODARD \& SOLLENBERGER, 2011), além de atender a legislação ambiental. O uso da cama de aviário nos solos agricultáveis do Sudoeste do Paraná tem ocorrido em larga escala, porém com pouca base científica, ou seja, os produtores utilizam, de forma geral, as doses que lhes convierem sem acompanhamento do resultado desta prática sobre a fertilidade do solo, além das estratégias de manejo, utilizadas por eles em pastagens perenes, não estarem bem definidas (HELTON et al., 2008).

Baseado nessas considerações, o objetivo do presente trabalho foi avaliar o efeito da escarificação e a eficiência da adubação orgânica com cama de aves para recuperação da estrutura do solo em áreas de gramíneas perene para fenação e aumento de produtividade.

\section{MATERIAL E MÉTODOS}

O experimento foi conduzido no município de Chopinzinho no sudoeste do estado do Paraná, Brasil, tendo como coordenadas: $25^{\circ} 54$ ' 53" de latitude Sul e $52^{\circ} 32^{\prime} 28^{\prime \prime}$ de longitude Oeste, com altitude de $700 \mathrm{~m}$. Pelo mapa de solos do Estado do Paraná (BHERING \& SANTOS, 2008), a área de estudo pertence à unidade de mapeamento NVdf -
Nitossolo Vermelho distroférrico. O clima da região é Cfa (subtropical, úmido), segundo classificação de Koppen. A área vinha sendo utilizada há dez anos para produção de feno de Tifton 85 , com três a quatro cortes da gramínea por ano, dependendo das condições climáticas. Em setembro de 2011, realizou-se uma coleta de solo na profundidade de 0,0-0,10m, para caracterização química (EMBRAPA, 1997) da área, que apresentou os seguintes resultados: $\mathrm{pH}$ em $\mathrm{CaCl}_{2}=5,5$; saturação por bases= $75 \%$; 28,7 e $162,2 \mathrm{mg} \mathrm{dm}^{-3}$ de potássio e fósforo, respectivamente; 9,93 e $2,64 \mathrm{cmol}_{\mathrm{c}} \mathrm{dm}^{-3}$ de cálcio e magnésio, respectivamente; e $59 \mathrm{~g} \mathrm{dm}^{-3}$ de matéria orgânica. A composição granulométrica do solo foi determinada pelo método da pipeta, sendo de 751, $227,22 \mathrm{~g} \mathrm{~kg}^{-1}$ de argila, silte e areia, respectivamente. A caracterização da densidade do solo (Ds) foi realizada nas profundidades de $0,05-0,10 ; 0,10-0,15$ e $0,20-0,25 \mathrm{~m}$, com valores de 1,$21 ; 1,23$ e $1,21 \mathrm{Mg}$ $\mathrm{m}^{-3}$, respectivamente.

O delineamento experimental utilizado foi em blocos ao acaso, com parcelas subdivididas, em esquema fatorial 2x6 (manejo do solo $\mathrm{x}$ adubação) e quatro repetições. Cada subparcela constou de $12 \mathrm{~m}^{2}$ $(3 \mathrm{x} 4 \mathrm{~m})$. O fator manejo do solo foi alocado na parcela principal, tendo como tratamentos: solo escarificado e solo não escarificado, tratamento realizado uma única vez no início do experimento (21/10/2011). O fator adubação foi alocado nas subparcelas, tendo como tratamentos: a) cama de aves na primavera, com reaplicação de $\mathrm{N}$ mineral nos cortes $(\mathrm{AO}+\mathrm{N})$; b) cama de aves na primavera (AO); c) adubação mineral NPK na primavera, com reaplicação de $\mathrm{N}$ mineral nos cortes $(\mathrm{AM}+\mathrm{N})$; d) adubação mineral NPK na primavera (AM); e) aplicação de $\mathrm{N}$ nos cortes $(\mathrm{T}+\mathrm{N})$; f) testemunha $(\mathrm{T})$.

O manejo do solo foi realizado com um escarificador com sete hastes parabólicas, discos de corte e com rolo destorroador/nivelador, a uma profundidade média de $0,25 \mathrm{~m}$. A adubação foi realizada com expectativa de produção de $25 \mathrm{tha}^{-1}$ de Tifton 85, segundo as recomendações técnicas para a cultura (COMISSÃO DE QUÍMICA E FERTILIDADE DO SOLO (CQFS)-RS/SC, 2004) e os níveis de nutrientes no solo. Nos tratamentos com cama de aves, foram aplicados $6.700 \mathrm{~kg} \mathrm{ha}^{-1}$, dose estabelecida a partir do teor de $\mathrm{P}_{2} \mathrm{O}_{5}$ no adubo orgânico (2,05\% de N, 5,5\% de $\mathrm{P}_{2} \mathrm{O}_{5}$ e 6,8\% de $\left.\mathrm{K}_{2} \mathrm{O}\right)$, utilizando os índices de eficiência dos nutrientes no solo para a cama de frango de corte $(0,5 ; 0,8$ e 1,0$)$ propostos por CQFS-RS/SC (2004), sendo adicionado o equivalente a $51,5 \mathrm{~kg}$ de $\mathrm{N}, 220 \mathrm{~kg}$ de $\mathrm{P}_{2} \mathrm{O}_{5}$ e $342 \mathrm{~kg}$ de $\mathrm{K}_{2} \mathrm{O}$. Os tratamentos com adubação mineral 
receberam por hectare: $127,5 \mathrm{~kg}$ de $\mathrm{N}, 220 \mathrm{~kg}$ de $\mathrm{P}_{2} \mathrm{O}_{5}$ e $350 \mathrm{~kg}$ de $\mathrm{K}_{2} \mathrm{O}$, utilizando-se ureia, superfosfato simples e cloreto de potássio, respectivamente. Após cada corte da gramínea, foi aplicado o tratamento com $\mathrm{N}$ mineral, constando de $127,5 \mathrm{~kg} \mathrm{ha}^{-1}$ de $\mathrm{N}$, na forma de ureia, totalizando $510 \mathrm{~kg} \mathrm{ha}^{-1} \mathrm{de} \mathrm{N}$.

Ao longo do período experimental, foram realizados quatro cortes da Tifton 85 , tendo como critério a altura das plantas $(0,45 \mathrm{~m})$. Todos os cortes foram realizados simultaneamente, com a finalidade de manter as mesmas condições para a reaplicação do $\mathrm{N}$. Após a coleta das amostras, as plantas foram cortadas e enfardadas mecanicamente para fenação. $\mathrm{O}$ cálculo do rendimento da massa seca (MS) por hectare foi realizado a partir da avaliação da produtividade de $0,5 \mathrm{~m}^{2}$. Pela somatória dos quatro cortes realizados, obteve-se o rendimento acumulado durante o período experimental.

Para determinação da Ds, porosidade total (PT), macroporos (MaP) e microporos (MiP), foram coletadas amostras indeformadas de solo, com auxílio de anéis metálicos $(0,065 \mathrm{~m}$ de diâmetro e $0,03 \mathrm{~m}$ de altura), em três profundidades: 0,03-0,08; 0,10-0,15 e 0,20-0,25m (EMBRAPA, 1997). No manejo do solo escarificado, realizou-se coleta de dois anéis na linha da haste do escarificador e dois anéis na entre linha escarificada, para cada profundidade, sendo doze anéis por parcela e, nos tratamentos sem escarificação, seis anéis por parcela, totalizando 432 amostras em cada avaliação. As avaliações foram realizadas aos 80 e aos 270 dias após a instalação do experimento, correspondentes a após o primeiro corte e após os quatro corte, respectivamente.

As variáveis do solo e a MS da Tifton 85 foram submetidas à análise de variância para determinar o nível de significância das fontes de variação. Para as variáveis do solo, foi realizada a análise de variância isolada para cada uma das três profundidades avaliadas. Para os parâmetros que apresentaram significância $(\mathrm{P}<0,05)$, realizou-se a comparação de médias pelo teste de Tukey a $5 \%$ de probabilidade. As análises foram realizadas com a utilização do programa estatístico SISVAR.

\section{RESULTADOS E DISCUSSÃO}

Para a primeira avaliação na profundidade de 0,10-0,15m, onde não houve escarificação, a Ds (Tabela 1) encontrava-se com valor considerado restritivo $\left(1,25 \mathrm{Mg} \mathrm{m}^{-3}\right)$ para o desenvolvimento das plantas. Os valores encontrados na literatura para Ds crítica estão entre 1,25 a $1,30 \mathrm{Mg} \mathrm{m}^{-3}$, para solos de textura muito argilosa (REICHERT et al., 2003). Sem a escarificação, a porcentagem de MaP foi de $8,7 \%$, inferior ao limite crítico de $10 \%$ (DEXTER, 1988) nas profundidades de 0,10-0,15 e 0,20-0,25, que pode restringir o crescimento de raízes, afetando a respiração do sistema radicular, pois os MaP são os principais responsáveis pela infiltração de água e fluxo de gases no solo (KRUMMELBEIN et al., 2008). Além disso, na profundidade de 0,03-0,08m, a porcentagem de MaP no solo não escarificado foi, aproximadamente, $9 \%$ inferior ao do solo escarificado. A escarificação diminuiu a compactação do solo pela redução da Ds, de 1,25 para $1,12 \mathrm{Mg} \mathrm{m}^{-3}$, e da MiP, e aumentou a PT e MaP, nas três profundidades avaliadas, 80 dias após o manejo do solo (Tabela 1). Essas alterações devem-se às fissuras criadas pela passagem das hastes do escarificador, propiciando o

Tabela 1 - Densidade do solo (Ds), porosidade total (PT), macroporos (MaP) e microporos (MiP), após o primeiro e o quarto corte da Tifton 85 ( 80 e 270 dias após a escarificação), submetida a diferentes manejos do solo (não escarificado e escarificado).

\begin{tabular}{|c|c|c|c|c|c|c|c|c|}
\hline \multirow{2}{*}{ Manejo do Solo } & \multicolumn{2}{|c|}{ Ds $\left(\mathrm{Mg} \mathrm{m}^{-3}\right)$----- } & \multicolumn{2}{|c|}{-------- PT (\%) ----------. } & \multicolumn{2}{|c|}{------- MaP (\%)--------- } & \multicolumn{2}{|c|}{----- MiP (\%) ------. } \\
\hline & 80 dias & 270 dias & 80 dias & 270 dias & 80 dias & 270 dias & 80 dias & 270 dias \\
\hline & \multicolumn{8}{|c|}{ 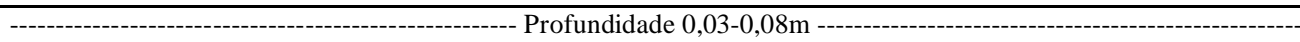 } \\
\hline Não Escarificado & $1,20 \mathrm{a}^{*}$ & $1,15 \mathrm{a}$ & $59,91 \mathrm{~b}$ & $65,57 \mathrm{~b}$ & $10,42 \mathrm{~b}$ & $11,39 \mathrm{~b}$ & $49,48 \mathrm{a}$ & $54,17 \mathrm{a}$ \\
\hline Escarificado & $1,02 \mathrm{~b}$ & $1,03 \mathrm{~b}$ & $66,1 \mathrm{a}$ & $69,67 \mathrm{a}$ & $19,68 \mathrm{a}$ & $20,32 \mathrm{a}$ & $46,42 \mathrm{~b}$ & $49,34 \mathrm{~b}$ \\
\hline CV $(\%)$ & 5,54 & 4,68 & 3,67 & 3,65 & 20,43 & 21,27 & 5,71 & 4,76 \\
\hline & & & & Profundid & $, 10-0,15 \mathrm{~m}$ & & & \\
\hline Não Escarificado & $1,25 \mathrm{a}$ & $1,21 \mathrm{a}$ & $58,08 \mathrm{~b}$ & $64,14 b$ & $8,72 \mathrm{~b}$ & $10,40 \mathrm{~b}$ & $49,36 \mathrm{a}$ & $53,73 \mathrm{a}$ \\
\hline Escarificado & $1,12 \mathrm{~b}$ & $1,11 \mathrm{~b}$ & $62,01 \mathrm{a}$ & $67,43 \mathrm{a}$ & $15,36 \mathrm{a}$ & $16,98 \mathrm{a}$ & $46,64 \mathrm{~b}$ & $50,44 \mathrm{~b}$ \\
\hline \multirow[t]{2}{*}{$\mathrm{CV}(\%)$} & 4,54 & 3,50 & 4,95 & 3,29 & 23,25 & 16,95 & 4,59 & 3,20 \\
\hline & & & & Profundid & $, 20-0,25 n$ & & & \\
\hline Não Escarificado & $1,18 \mathrm{a}$ & $1,16 \mathrm{a}$ & $60,00 \mathrm{~b}$ & $65,55 \mathrm{a}$ & $8,53 \mathrm{~b}$ & $10,63 \mathrm{a}$ & $51,46 \mathrm{a}$ & $54,92 \mathrm{a}$ \\
\hline Escarificado & $1,12 \mathrm{~b}$ & $1,14 \mathrm{a}$ & $62,06 \mathrm{a}$ & $65,90 \mathrm{a}$ & $13,13 \mathrm{a}$ & $12,10 \mathrm{~b}$ & $48,93 \mathrm{~b}$ & $53,79 \mathrm{~b}$ \\
\hline $\mathrm{CV}(\%)$ & 4,25 & 3,26 & 3,96 & 2,51 & 22,15 & 15,91 & 4,8 & 2,91 \\
\hline
\end{tabular}

*Médias seguidas pelas mesmas letras minúsculas na vertical não diferem estatisticamente entre si, pelo teste de Tukey a 5\%. CV: coeficiente de variação. 
aumento da infiltração de água, aumentando os ciclos de molhamento e secagem do solo, influindo na sua reestruturação e definindo uma nova porosidade (COLET et al., 2009).

A duração do efeito da escarificação foi constatada mesmo após os 270 dias (Tabela 1), com diferença na Ds, PT, MaP e MiP, para as profundidades de 0,03-0,08 e 0,10-0,15 m, e na MaP e MiP para a profundidade de 0,20-0,25m. $\mathrm{Na}$ segunda avaliação, no solo não escarificado, na profundidade de $0,10-0,15 \mathrm{~m}$, o valor da Ds foi de $1,21 \mathrm{Mg} \mathrm{m}^{-3}$, inferior ao valor crítico encontrado na literatura. Contudo, na avaliação de caracterização para a mesma profundidade, o valor da Ds foi de $1,23 \mathrm{Mg} \mathrm{m}^{-3}$, também inferior ao valor crítico, estando o resultado relacionado com a variabilidade espacial e temporal deste atributo no solo. A segunda avaliação foi realizada três meses após o quarto corte e a gramínea estava em período de estacionalidade de produção, diminuindo o crescimento da parte aérea e aumentando o desenvolvimento de estolões e raízes (REIS et al., 2005), o que também pode ter influenciado em valores menores para a Ds.

Considerando o intenso tráfego de máquinas na lavoura para as operações de fenação, esperava-se que os efeitos não permanecessem por 270 dias. O que pode ter contribuído para essa persistência foi o grande aporte de estolões da Tifton 85 na superfície do solo, atuando como amortecedor nas pressões exercidas pelos pneus das máquinas e implementos, conferindo maior estabilidade aos agregados do solo. A escarificação pode ter favorecido o desenvolvimento das raízes (observado visualmente no campo) na camada mais adensada de $0,10-0,15 \mathrm{~m}$ de profundidade, devido ao incremento da disponibilidade de água para as plantas, que, somada a uma adubação adequada para a Tifton 85 , proporcionou aumento na densidade de raízes, dificultando e retardando o tempo de retorno do solo à condição inicial de compactação. As raízes causam uma pressão mecânica com o seu crescimento e proporcionam o secamento no solo ao seu redor, aproximando e aumentando a coesão entre partículas; elas também exsudam carboidratos que são fonte de carbono lábil para os microrganismos que intensificam a sua atividade e a produção de polissacarídeos, auxiliando na estabilização de agregados (BRAIDA et al., 2011). Redução significativa da Ds e aumento de MaP do solo com o cultivo da Tifton 85 foram observados por MAGALHÃES et al. (2009), que atribuem a recuperação da estrutura do solo à atividade das raízes, porém com comprometimento no rendimento dos primeiros cortes, devido ao gasto de energia metabólica através do transporte de fotossintetizados da parte aérea às raízes para o rompimento da camada compactada.

$O$ rendimento da MS da Tifton 85 no primeiro corte (Tabela 2) foi prejudicado em $27,82 \%$

Tabela 2 - Produtividade em cada corte e acumulada (Total) da Tifton 85, submetida a diferentes manejos do solo e adubações (adubação orgânica (AO); adubação mineral (AM); e testemunha (T), sem e com reposição de $\mathrm{N}(+\mathrm{N})$ nos cortes).

\begin{tabular}{|c|c|c|c|c|c|c|c|c|}
\hline \multicolumn{2}{|l|}{ Tratamento } & $\mathrm{AO}+\mathrm{N}$ & $\mathrm{AO}$ & $\mathrm{AM}+\mathrm{N}$ & $\mathrm{AM}$ & $\mathrm{T}+\mathrm{N}$ & $\mathrm{T}$ & Média \\
\hline \multirow{3}{*}{$1^{\circ}$ Corte } & Não Esc & 5.056 & 4.143 & 6.840 & 6.834 & 6.050 & 2.939 & $5.310 \mathrm{~A}$ \\
\hline & Esc & 3.116 & 3.455 & 4.951 & 4.810 & 4.495 & 2.170 & $3.833 \mathrm{~B}$ \\
\hline & Média & $4.086 b^{*}$ & $3.799 \mathrm{~b}$ & $5.896 \mathrm{a}$ & $5.822 \mathrm{a}$ & $5.273 \mathrm{a}$ & $2.554 \mathrm{c}$ & \\
\hline \multirow{3}{*}{$2^{\circ}$ Corte } & Não Esc & $5.930 \mathrm{aA}^{*}$ & $4.680 \mathrm{bB}$ & $5.800 \mathrm{aB}$ & $4.460 \mathrm{bB}$ & $5.280 \mathrm{abB}$ & $4.600 \mathrm{bA}$ & 5.125 \\
\hline & Esc & $6.370 \mathrm{abA}$ & $5.720 \mathrm{bcA}$ & $6.760 \mathrm{abA}$ & $6.220 \mathrm{abA}$ & $7.140 \mathrm{aA}$ & $4.840 \mathrm{cA}$ & 6.175 \\
\hline & Média & 6.150 & 5.200 & 6.280 & 5.340 & 6.210 & 4.720 & \\
\hline \multirow{3}{*}{$3^{\circ}$ Corte } & Não Esc & 3.970 & 2.790 & 3.780 & 2.610 & 4.160 & 2.610 & $3.320 \mathrm{~B}$ \\
\hline & Esc & 4.370 & 3.210 & 4.680 & 3.100 & 3.840 & 3.060 & $3.710 \mathrm{~A}$ \\
\hline & Média & $4.170 \mathrm{a}^{*}$ & $3.000 \mathrm{a}$ & $4.230 \mathrm{a}$ & $2.855 \mathrm{~b}$ & $4.000 \mathrm{a}$ & $2.835 \mathrm{~b}$ & \\
\hline \multirow{3}{*}{$4^{\mathrm{o}}$ Corte } & Não Esc & 5.080 & 2.040 & 5.730 & 2.100 & 5.100 & 2.300 & $3.725 \mathrm{~A}$ \\
\hline & Esc & 5.910 & 2.020 & 5.120 & 1.940 & 4.050 & 1.820 & $3.476 \mathrm{~A}$ \\
\hline & Média & $5.495 \mathrm{a}^{*}$ & $2.030 \mathrm{c}$ & $5.425 \mathrm{ab}$ & $2.020 \mathrm{c}$ & $4.575 b$ & $2.060 \mathrm{c}$ & \\
\hline \multirow{3}{*}{ Total MS } & Não Esc & 20.036 & 13.653 & 22.150 & 16.004 & 20.590 & 12.449 & $17.480 \mathrm{~A}$ \\
\hline & Esc & 19.766 & 14.405 & 21.511 & 16.070 & 19.525 & 11.890 & 17.194 A \\
\hline & Média & $19.901 b^{*}$ & $14.029 \mathrm{~d}$ & $21.830 \mathrm{a}$ & $16.037 \mathrm{c}$ & $20.057 \mathrm{~b}$ & $12.169 \mathrm{e}$ & \\
\hline
\end{tabular}

*Médias seguidas pela mesma letra maiúscula para manejo do solo e minúsculas para adubação não diferem estatisticamente entre si pelo teste de Tukey a $5 \%$. 
com a escarificação do solo, estando relacionado ao dano que o escarificador pode provocar no sistema radicular (BOMFIM et al., 2003). Como o primeiro corte foi realizado 61 dias após a escarificação, não houve tempo suficiente para a gramínea se recuperar do dano às raízes, comprometendo a absorção de água e nutrientes e, consequentemente, a produtividade. Com a realização da escarificação no início do inverno, após o último corte, talvez se proporcione maior tempo para a forrageira se recuperar dos danos, aumentando o volume de raízes no período de estacionalidade de produção, resultando numa maior produção no primeiro corte, no tratamento escarificado. No segundo corte (Tabela 2), 103 dias após a escarificação, percebe-se uma recuperação da gramínea, em função da Tifton 85 apresentar elevada densidade e periódica renovação radicular, resultando em maior rendimento de MS com a escarificação para os tratamentos $\mathrm{AO}, \mathrm{AM}+\mathrm{N}, \mathrm{AM}$ e $\mathrm{T}+\mathrm{N}$. Apenas para a testemunha não houve diferença entre os manejos, justificado pela menor disponibilidade de nutrientes.

Em relação aos tratamentos com adubação, a resposta da Tifton 85 no primeiro corte (Tabela 2) foi maior com a aplicação da fonte mineral, $\mathrm{AM}+\mathrm{N}$ e $\mathrm{AM}$, não diferindo do tratamento $\mathrm{T}+\mathrm{N}$, pois os teores de $\mathrm{P}$ e $\mathrm{K}$ no solo eram altos no início do experimento. Esses resultados evidenciam uma resposta apenas ao $\mathrm{N}$ mineral aplicado, uma vez que o $\mathrm{N}$, frequentemente, apresenta maior impacto sobre a produção da Tifton 85 (WOODARD \& SOLLENBERGER, 2011). O $\mathrm{N}$ aumenta a eficiência fotossintética da folha por estimular a síntese de rubisco, enzima chave nas reações bioquímicas de assimilação do carbono (PEREIRA et al., 2012), favorecendo o perfilhamento inicial após o corte, com aumento da interceptação luminosa, e reduzindo o tempo de balanço energético negativo, devido a cortes drásticos da parte aérea, acelerando a formação e crescimento de folhas (REIS et al., 2005).

A produtividade nos tratamentos com AO foram inferiores aos com AM (Tabela 2). Embora as quantidades de $\mathrm{N}$ adicionado com a cama de aves estivessem próximas da adicionada com ureia, estimase que apenas metade deste $\mathrm{N}$ pôde ser aproveitada pelas plantas até o primeiro corte. Devido ao período necessário para mineralização do resíduo, as plantas que receberam AO tiveram uma menor disponibilidade de $\mathrm{N}$, justificando a menor produtividade obtida nesses tratamentos em relação aos que receberam fonte mineral, onde os nutrientes estão em formas solúveis, estando prontamente disponíveis às plantas. Outra característica da cama de aves é que as formas de $\mathrm{N}$ presentes são mineralizadas como $\mathrm{NH}_{4}^{+} \mathrm{e}$, se mantidas na superfície, propiciam perdas por volatilização.
A resposta à adubação no terceiro corte (Tabela 2) foi maior nos tratamentos que receberam $\mathrm{N}$ a cada corte $(\mathrm{AO}+\mathrm{N}, \mathrm{AM}+\mathrm{N}$ e $\mathrm{T}+\mathrm{N})$. Mesmo que a $\mathrm{AO}$ proporcione uma liberação mais lenta do N, a contribuição do $\mathrm{N}$ residual já não é mais detectada no terceiro corte, havendo necessidade de novo suprimento de $\mathrm{N}$ para a gramínea, uma vez que o $\mathrm{N}$ adicionado pela cama de aves equivaleu a um quarto da necessidade da cultura. $\mathrm{O}$ mesmo comportamento foi observado no quarto corte (Tabela 2), com maior produtividade no tratamento $\mathrm{AO}+\mathrm{N}\left(5.495 \mathrm{~kg} \mathrm{ha}^{-1}\right)$, seguido pelo $\mathrm{AM}+\mathrm{N}\left(5.425 \mathrm{~kg} \mathrm{ha}^{-1}\right)$. Os resultados mostram a importância da aplicação de $\mathrm{N}$ mineral após o corte da Tifton 85, como forma de estimular o crescimento da gramínea. Embora não avaliada neste trabalho, a suplementação com $\mathrm{N}$ mineral nos cortes parece ser mais eficiente do que uma reaplicação com cama de aves, tendo em vista o período necessário para a mineralização do resíduo e os riscos de acúmulo de outros elementos que são absorvidos em menor quantidade pelas plantas.

O rendimento acumulado da MS dos quatro cortes (Tabela 2) apresentou diferença significativa apenas para as adubações, mesmo com a produção do primeiro corte comprometida pelo dano às raízes ocasionado pelo escarificador, não houve diferença significativa para os manejos do solo. Nas adubações, as maiores produtividades foram nos tratamentos $\mathrm{AM}+\mathrm{N}$, seguido do $\mathrm{AO}+\mathrm{N}$ e $\mathrm{T}+\mathrm{N}$, que receberam maiores quantidades de N. A adubação com cama de aves não apresentou maior contribuição de MS, comparada à adubação mineral, considerando toda a produção de forragem em uma estação de crescimento da Tifton 85. Porém, deve-se levar em consideração que a cama de aves é um insumo disponível na propriedade que precisa ser disponibilizado adequadamente. Assim, aspectos econômicos e ambientais devem ser analisados para a definição da fonte de nutrientes a ser utilizada. A diferença de custo do tratamento $\mathrm{AO}+\mathrm{N}$ e $\mathrm{AM}+\mathrm{N}$ foi de $\mathrm{R} \$ 67,00$ por tonelada de MS produzida a mais para o segundo tratamento (Tabela 3), tendo um custo por tonelada de 1,7 vezes superior nos tratamentos com fonte mineral que receberam $\mathrm{N}$ adicional a cada corte. Porém, o fornecimento de outros nutrientes essenciais às plantas, com destaque para os micronutrientes, e que não estão presentes nos fertilizantes minerais, pode ser uma vantagem do uso de resíduos orgânicos (CQFS$\mathrm{RS} / \mathrm{SC}, 2004)$.

\section{CONCLUSÃO}

A escarificação esporádica em áreas destinadas à fenação, produzindo Tifton 85 , é efetiva 
Tabela 3 - Custo das adubações por hectare e por tonelada de massa seca (MS) produzida com diferentes adubações (adubação orgânica (AO); adubação mineral (AM); e testemunha (T), sem e com reposição de $\mathrm{N}(+\mathrm{N})$ nos cortes).

\begin{tabular}{llllll}
\hline Tratamento & $\mathrm{AO}+\mathrm{N}$ & $\mathrm{AO}$ & $\mathrm{AM}+\mathrm{N}$ & $\mathrm{AM}$ & $\mathrm{T}+\mathrm{N}$ \\
\hline $\mathrm{MS}\left(\mathrm{Kg} \mathrm{ha}^{-1}\right)$ & 19.901 & 14.029 & 21.831 & 16.037 & 20.058 \\
$\mathrm{R} \$ \mathrm{ha}^{-1}$ & $1.739,50$ & 670,00 & $3.380,48$ & $2.310,98$ & $1.426,08$ \\
$\mathrm{R}$ / tonelada & 87,40 & 47,75 & 154,85 & 144,10 & 71,09 \\
\hline
\end{tabular}

para melhorar e manter a qualidade física do solo por pelo menos nove meses.

A escarificação do solo no mês de outubro para áreas com Tifton 85 não é recomenda, pois não ocorre tempo suficiente para a gramínea se recuperar do dano às raízes ocasionado pelo escarificador, comprometendo a produção do primeiro corte.

A complementação com $\mathrm{N}$ mineral após os cortes é fundamental para obter altas produtividades da gramínea.

\section{AGRADECIMENTOS}

Ao Conselho Nacional de Desenvolvimento Científico e Tecnológico $(\mathrm{CNPq})$ pela bolsa de mestrado concedida Ao Dr. Luis César Cassol da Universidade Tecnológica Federal do Paraná (UTFPR) - Campus Pato Branco, por ceder o laboratório de solos para as avaliações do experimento.

\section{REFERÊNCIAS}

BHERING, S.B.; SANTOS, H.G. dos. Mapa de solos do Estado do Paraná: legenda atualizada. Rio de Janeiro: EMBRAPA/ IAPAR, 2008. 74p

BOMFIM, E.R.P. et al. Efeito do tratamento físico associado à adubação em pastagem degradada de Braquiária, nos teores de proteína bruta, fibra em detergente neutro e fibra em detergente ácido. Ciência Agrotécnica, v.27, n.4, p.912-900, 2003. Disponível em: <http://www.scielo.br/pdf/cagro/v27n4/ v27n4a25.pdf $>$. Acesso em: 02 jun. 2013. doi: 10.1590/S141370542003000400025 .

BRAIDA, J.A. et al. Matéria orgânica e seu efeito na física do solo. In: ___ Tópicos em ciência do solo. Viçosa: Sociedade Brasileira de Ciência do Solo, 2011. V.7, p.222-227.

COLET, M.J. et al. Alteração em atributos físicos de um solo sob pastagem após escarificação. Ciência Agrotécnica, v.33, n.2, p.361-368, 2009. Disponível em: <http://www.scielo.br/ pdf/cagro/v33n2/v33n2a01.pdf $>$. Acesso em: 02 jun. 2013. doi: 10.1590/S1413-70542009000200001.

COMISSÃO DE QUÍMICA E FERTILIDADE DO SOLO. Manual de adubação e de calagem para os estados do RS e SC. 10.ed. Porto Alegre: Sociedade Brasileira de Ciência do Solo Núcleo Regional Sul, 2004. 394p.

DEXTER, A.R. Advances in characterization of soil structure. Soil \& Tillage Research, v.11,p.199-238, 1988. Disponível em: <http:// www.sciencedirect.com/science/article/pii/0167198788900025>. Acesso em: 02 jun. 2013. doi: 10.1016/0167-1987(88)90002-5.
EMBRAPA, Centro Nacional de Pesquisa de Solos. Manual de métodos de análise de solos. Revisado e atual. Rio de Janeiro: EMBRAPA, 1997. 212p.

GIAROLA, N.F.B. et al. Degradação física de um Latossolo Vermelho utilizado para produção intensiva de forragem. Revista Brasileira de Ciência do Solo, v.31, n.5 p.863-873, 2007. Disponível em: <http://www.scielo.br/pdf/rbcs/v31n5/ a04v31n5.pdf >. Acesso em: 02 jun. 2013. doi: 10.1590/S010006832007000500004 .

HELTON, T.J. et al. Effects of dairy manure compost and supplemental inorganic fertilizer on Coastal Bermudagrass. Agronomy Journal, v.100, n.4, p.924-930. 2008. Disponível em: <https://www.agronomy.org/publications/aj/pdfs/100/4/924>. Acesso em: 02 jun. 2013. doi: 10.2134/agronj2007.0305.

KRUMMELBEIN, J. et al. Determination of pre-compression stress of a variously grazed steppe soil under static and cyclic loading. Soil \& Tillage Research, v.99, p.139-148, 2008. Disponível em: <http://www.sciencedirect.com/science/article/pii/ S0167198708000214>. Acesso em: 02 jun. 2013. doi: 10.1016/j. still.2008.01.008

MAGALHÃES, E.N. et al. Recuperação estrutural e produção de capim Tifton 85 em um Argissolo Vermelho-Amarelo compactado. Ciência Animal Brasileira, v.10, n.1, p.68-76, 2009. Disponível em: <www.revistas.ufg.br/index.php/vet/article/ download/2211/4572>. Acesso em: 02 jun. 2013.

PEREIRA, O.G. et al. Crescimento do capim-tifton 85 sob doses de nitrogênio e alturas de corte. Revista Brasileira de Zootecnia, v.41, n.1, p.30-35, 2012. Disponível em: <http://www.scielo.br/ pdf/rbz/v41n1/05.pdf>. Acesso em: 02 jun. 2013. doi: 10.1590/ S1516-35982012000100005.

REICHERT, J.M. et al. Qualidade dos solos e sustentabilidade de sistemas agrícolas. Revista Ciência \& Ambiente, v.27, n.2, p.29-48, 2003. Disponível em: $<$ http://www.fisicadosolo.ccr.ufsm. quoos.com.br/downloads/Producao_Artigos/5.pdf>. Acesso em: 02 jun. 2013

REICHERT, J.M. et al. Compactação do solo em sistemas agropecuários e florestais: identificação, efeitos, limites críticos e mitigações. In: ___. Tópicos em ciência do solo. Viçosa: Sociedade Brasileira de Ciência do Solo, 2007. V.5, p.49-134.

REIS, R.A. et al. Produção de fenos de Cynodon. In: Cynodon: forrageiras que estão revolucionando a pecuária brasileira. Juiz de Fora: Embrapa Gado de Leite, 2005. 250p. Cap.4, p.79-131.

WOODARD, K.; SOLLENBERGER, L.E. Broiler Litter vs. Ammonium nitrate as nitrogen source for bermudagrass hay production: yield, nutritive value, and nitrate leaching. Crop Science, v.51, n.3 p.1342-1352, 2011. Disponível em: <https:// www.crops.org/publications/cs/articles/51/3/1342>. Acesso em: 02 jun. 2013. doi: 10.2135/cropsci2010.06.0342. 